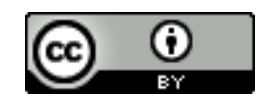

Esta obra está sob o direito de Licença Creative Commons Atribuição 4.0 Internacional.

\title{
INCLUSÃO ESCOLAR: UMA PRATICA SOCIAL
}

\author{
Cassiane Alves Santos Bispo ${ }^{1}$ \\ Ivaci Bonfim Pinheiro ${ }^{2}$ \\ Elizabeth Calheiros Borges ${ }^{3}$ \\ Wesley dos Santos Lima ${ }^{4}$ \\ Eliete dos Santos Silva \\ Amara Mari de Lima Buarque 6
}

\section{RESUMO}

Sabemos que já não é aceitável uma escola que exclui e faz diferença entre seus educandos, pois todos são “especiais" já que cada um traz consigo suas diferenças, medos e anseios. Á vista disto, este artigo tem como objetivo compreender a importância da inclusão escolar como uma prática social fundamental para um bom andamento da sociedade na qual vivemos. A pesquisa buscou reconhecer os fatores que influenciam a inclusão social e os fatores sociais, analisando produções científicas publicadas entre 2016 e 2020, no Scielo. Trata-se de uma revisão sistemática. Utilizando os descritores estruturados no DeCS e MeSH. O período de coleta dos dados ocorreu em abril/2021. Adotaram-se como critérios de inclusão artigo científicos e, como critérios de exclusão artigos que não contemplam a temática estudada. Portanto, é preciso que a escola seja algo estimulante onde os educandos sintam-se seguros e acolhidos acontecendo assim à inclusão de fato já que o acesso e permanência à mesma é direito de todos.

PALAVRAS-CHAVE: Inclusão. Escola. Sociedade. Respeito às diferenças.

\footnotetext{
1 profcassiane2014@gmail.com.

2 ivaci18@outlook.com

${ }^{3}$ bethcalheirosborges@gmail.com

${ }^{4}$ wesleyecristo@gmail.com

5 ellyssilva@yahoo.com.

${ }^{6}$ amarabuarque@hotmail.com
} 


\section{INTRODUÇÃO}

Partindo do ponto de que todos têm diferenças e com elas necessidades especiais não podemos deixar de perceber que a comunidade escolar é um espaço onde encontramos várias formas de divergências, sendo assim todos devem ser tratados como “alunos especiais”, porém é indispensável que a forma e o tempo de aprendizagem de cada educando sejam respeitados em especial os educandos que apresentam NEE (Necessidade Educacional Especial).

É preciso que a educação inclusiva venha a ocorrer de fato como deve ser, para isso se faz fundamental o apoio adequado e especifico de que o educando precise para assim desenvolve-se de forma significativa e de qualidade, seja esse apoio tanto profissional como também material. Sendo assim é preciso que se reconheça qual grandioso e importante é esse caminho, cheio de desafios e dificuldades (SILVA, CARVALHO, 2017).

À vista disto, é preciso que reconheçamos a necessidade do docente ter diversos materiais de base como também especialistas que o auxiliem para assim poder criar diferentes acompanhamentos os quais tenham maleabilidade e dinamismo criando diversas formas de comunicação com todos que fazem parte da comunidade escolar inclusive a família já que a mesma si faz de suma importância pra o desenvolvimento intelectual do educando sendo ela o primeiro grupo social ao qual pertencemos (PESQUISA, 2021).

Entretanto é preciso esclarecer, o professor somente não consegui acabar com a exclusão no ambiente escolar, pois não é somente mudar os métodos de ensino e avaliativo, o professor precisa do apoio de toda comunidade escolar.

Contudo, é fundamental que se desenvolva um trabalho em equipe onde todos contribuam com sugestões às quais devem buscar fundamentos nos projetos curriculares e nas políticas públicas. É preciso valorizar a individualidade de cada um que faz parte dessa comunidade escolar buscando assim o desenvolvimento de valores que incluem e apoia o processo de aprendizagem o qual deve ser continuo, significativo e de qualidades onde todos sejam respeitados, pois as diferenças estão para serem entendidas e superadas (SILVA, CARVALHO, 2017).

\section{METODOLOGIA}

Trata-se de uma revisão bibliográfica, do tipo sistemático integrativa, que seguiu as seguintes etapas (ver quadro 1): definição do tema; seleção da pergunta norteadora e escolha 
da estratégia de busca; descritores e bases de dados mais eficazes no levantamento das publicações; escolha dos critérios de inclusão e exclusão; identificação dos estudos pré-selecionados e selecionados por meio da leitura dos agentes indexadores das publicações, como resumos, palavras-chave e títulos, bem como a organização dos estudos préselecionados e a identificação dos estudos selecionados; categorização dos estudos selecionados, com a elaboração e o uso da matriz de síntese, além da análise das informações; a formação de uma biblioteca individual e a avaliação crítica dos estudos selecionados; análise, interpretação e discussão dos resultados e a apresentação da revisão em formato de artigo, o qual contempla as propostas para estudos futuros.

Quadro 1 - Detalhamento das etapas da Revisão Sistemática Integrativa.

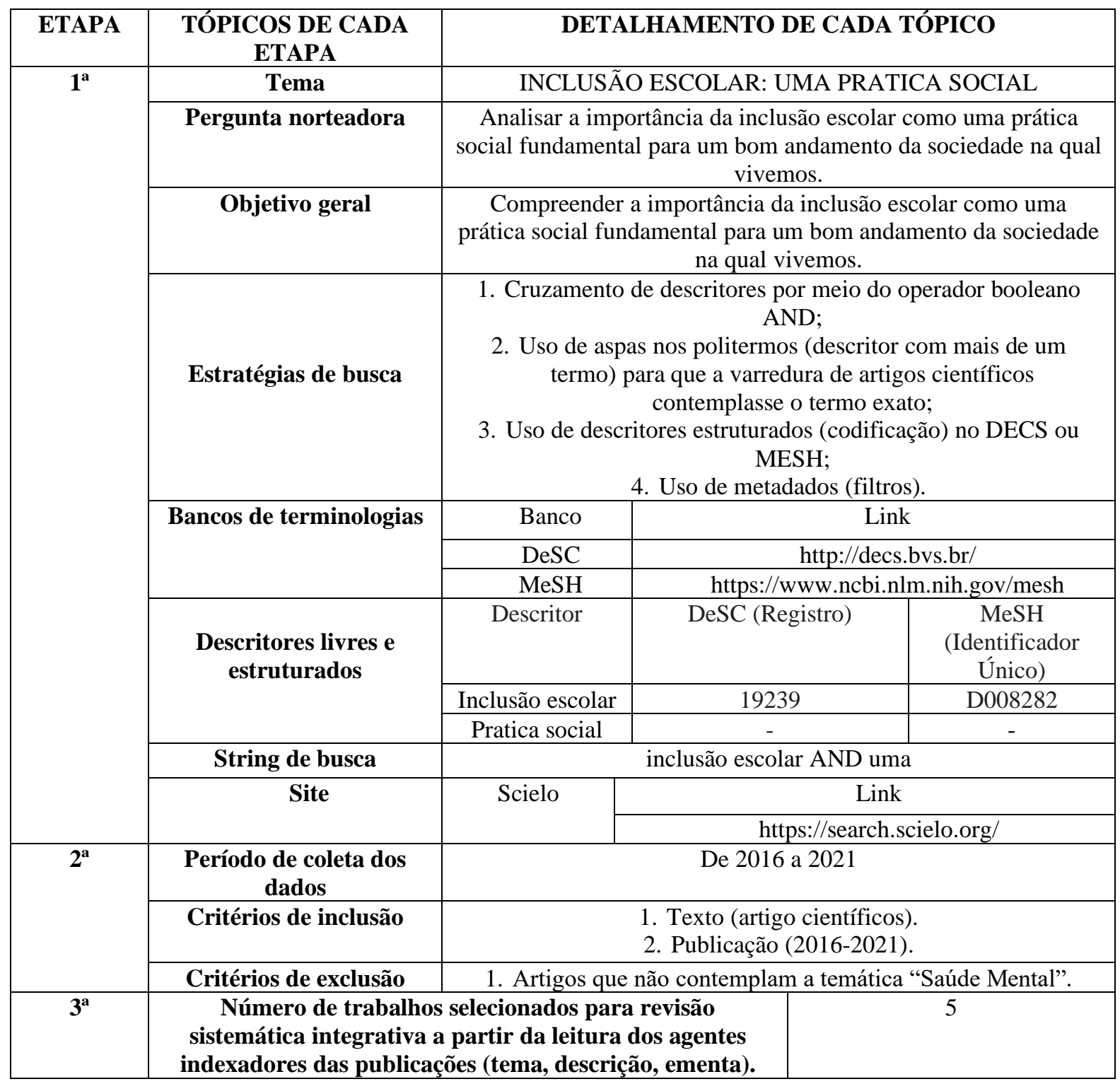




\begin{tabular}{|c|c|c|}
\hline $4^{\text {a }}$ & $\begin{array}{c}\text { Categorias obtidas com a análise dos documentos } \\
\text { investigados online gratuitos e de livre acesso }\end{array}$ & 2 \\
\hline
\end{tabular}

Fonte: elaborada pelos autores.

\section{RESULTADOS}

Quadro 2 - Corresponde ao total de documentos disponíveis na Plataforma Periódicos Capes obtidos por String de busca.

\begin{tabular}{|c|c|c|c|c|}
\hline String de busca & $\begin{array}{c}\text { Bases de } \\
\text { dados }\end{array}$ & $\begin{array}{c}\text { Total de } \\
\text { publicações } \\
\text { sem o filtro }\end{array}$ & $\begin{array}{c}\text { Publicações } \\
\text { disponíveis após } \\
\text { aplicar os filtros }\end{array}$ & $\begin{array}{c}\text { Publicações } \\
\text { aproveitadas na Revisão } \\
\text { Sistemática Integrativa }\end{array}$ \\
\hline $\begin{array}{c}\text { inclusão escolar } \\
\text { AND uma }\end{array}$ & Scielo & 23 & 8 & 5 \\
\hline
\end{tabular}

Fonte: elaborada pelos autores.

Quadro 3 - Descrição dos documentos (artigos) de acordo com os critérios de inclusão.

\begin{tabular}{|c|c|c|c|}
\hline Autor(a) & Tema & $\begin{array}{l}\text { Data de } \\
\text { publica } \\
\text { ção }\end{array}$ & Conclusão \\
\hline $\begin{array}{l}\text { Jáima Pinheiro de } \\
\text { OLIVEIRA2 Seán } \\
\text { BRACKEN3 Natália } \\
\text { NAKANO4 }\end{array}$ & $\begin{array}{l}\text { Indicadores } \\
\text { Preliminares do Uso } \\
\text { da Lesson Study } \\
\text { Como Prática de } \\
\text { Ensino Capaz de } \\
\text { Viabilizar uma } \\
\text { Perspectiva Inclusiva } \\
\text { na Educação } \\
\text { Superior }\end{array}$ & 2020 & $\begin{array}{l}\text { Os dados obtidos permitiram fazer alusões às } \\
\text { políticas e orientações existentes e geradas na } \\
\text { própria Universidade e, de modo particular, a } \\
\text { análise proporcionou o aprimoramento } \\
\text { profissional das professoras envolvidas, assim } \\
\text { como indicou possibilidades desse } \\
\text { aprimoramento em relação aos outros docentes } \\
\text { que possuem uma preocupação com a adoção } \\
\text { de ações com perspectivas de ensino inclusivo. }\end{array}$ \\
\hline $\begin{array}{c}\text { Luana Stela } \\
\text { Weizenmann; } \\
\text { Fernanda Aparecida } \\
\text { Szareski Pezzi; Regina } \\
\text { Basso Zanon }\end{array}$ & $\begin{array}{c}\text { INCLUSÃO } \\
\text { ESCOLAR E } \\
\text { AUTISMO:SENTIM } \\
\text { ENTOS E } \\
\text { PRÁTICAS } \\
\text { DOCENTES } \\
\end{array}$ & 2020 & $\begin{array}{c}\text { Com relação à prática pedagógica } \\
\text { foi verificado que os docentes realizaram } \\
\text { adequações pedagógicas de acordo com as } \\
\text { características de cada aluno. }\end{array}$ \\
\hline $\begin{array}{c}\text { Geraldo Pereira Maria } \\
\text { Inês Batista Barbosa } \\
\text { Luiz Augusto } \\
\text { Coimbra de Rezende } \\
\text { Filho }\end{array}$ & $\begin{array}{l}\text { Ouvindo imagens: } \\
\text { ensaio sobre uma } \\
\text { oficina audiovisual } \\
\text { inclusiva de cinema e } \\
\text { educação }\end{array}$ & 2019 & $\begin{array}{l}\text { Como resultado, identificamos que a } \\
\text { experiência da oficina propiciou formas } \\
\text { potentes de relação entre os participantes, como } \\
\text { fica evidente no próprio vídeo e no sistema } \\
\text { colaborativo da sua produção, acionado pela } \\
\text { força de um descontentamento social vivido } \\
\text { por eles no contexto escolar. }\end{array}$ \\
\hline $\begin{array}{l}\text { Naiane Cristina } \\
\text { SILVA Beatriz Girão } \\
\text { Enes CARVALHO }\end{array}$ & $\begin{array}{l}\text { Compreendendo o } \\
\text { Processo de Inclusão } \\
\text { Escolar no Brasil na } \\
\text { Perspectiva dos } \\
\text { Professores: uma } \\
\text { Revisão Integrativa }\end{array}$ & 2017 & $\begin{array}{l}\text { Sugerem-se novos estudos sobre as } \\
\text { contribuições efetivas dos profissionais de } \\
\text { outras áreas na estruturação de recursos e } \\
\text { estratégias de apoio a prática educacional. }\end{array}$ \\
\hline Flávia Lima Ciríaco & $\begin{array}{l}\text { Inclusão: um direito } \\
\text { de todos }\end{array}$ & 2021 & $\begin{array}{l}\text { Pelos questionamentos dos colegas de profissão } \\
\text { e na busca da fundamentação dessa nova } \\
\text { perspectiva de educação é que tomo a inclusão } \\
\text { como objeto de estudo, visando conhecer e } \\
\text { identificar os fatores que permeiam essa } \\
\text { proposta. }\end{array}$ \\
\hline
\end{tabular}

Fonte: Plataforma online Scielo, 2021. 
O corpo textual foi analisado por meio da frequência de palavras, que originou a nuvem de palavras (Figura 1) criada na Plataforma online WordArt. Esta ferramenta agrupa e organiza graficamente as palavras-chave evidenciando-as as mais frequentes.

Figura 1 - Nuvem de palavras

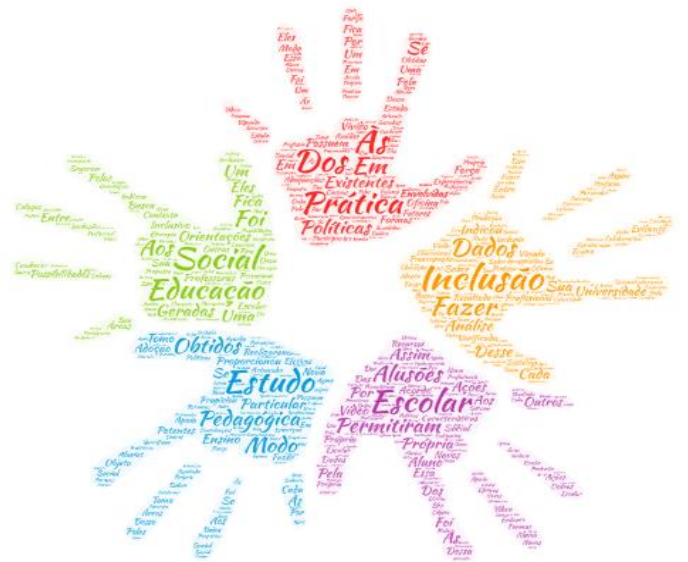

Fonte: elaborada pelos autores.

Por meio da Figura 1, foi possível observar que as palavras em evidência na nuvem pertencem às categorias desenvolvidas a partir da análise de conteúdo de Bardin. Todas as categorias derivam da sua frequência. Em consonância ao objetivo deste trabalho, optou-se por descrever as palavras que apresentaram frequência total no texto e, a partir de seus sentidos nos campos textuais, como apresentado na Figura1.

\section{DISCUSSÃO}

Seguem abaixo, as categorias temáticas elaboradas a partir da revisão sistemática integrativa.

\section{A ESCOLA É HETEROGENEIDADE.}

Escola, espaço de diversidade. Partindo dessa ideia é perceptível que entendamos a escola como uma comunidade onde se devem respeitar as diferenças nela exposta, sendo assim cabe a todos a todos reconhecerem que a inclusão é um processo pedagógico igualitário para todos os educandos, ou seja, se faz necessário a criação do desenvolvimento de métodos que venham a incluir dos todos os educandos, pois não é mais aceitável uma escola que tenha procedimentos educacionais baseados na seleção e exclusão de seus alunos (SILVA, CARVALHO, 2017).

Sendo assim, não basta assegurar a entrada dos educandos na comunidade escolar é preciso que se cie dispositivos que venham garantir a permanência dos mesmos no âmbito escolar.

Segundo MANTOAN,

Todo realinhamento do processo educacional para se compatibilizar com a inclusão gira em torno da adequação do processo escolar para que a singularidade dos alunos seja considerada em sua natureza mutante. A garantia do acesso de todos à escola comum é necessária, mas insuficiente para que a educação inclusiva se efetive em nossas redes de ensino. [...] (MANTOAN, 2014, p.7).

À vista disto, vemos que garantir o direito de acesso de todos 
independentes de suas necessidades educacionais no âmbito escolar não é o suficiente para si ter uma educação inclusiva de qualidade, pois, mais que direito ao acesso se faz essencial criar em nossa sociedade a cultura do respeito às diferenças criando mecanismo que venham a contribuir para a permanência de nossos educandos no espaço escolar.

\section{Para MANTOAN,}

A escola tem poderes para diferenciar e para identificar os alunos, submentendo-os a mecanismos de inclusão e exclusão. $\mathrm{O}$ poder de incluir relaciona-se com o sentido que atribuímos à diferenças das pessoas. Somos seres mutantes, que se diferenciam externa e internamente (para melhor ou para pior), conforme nossas condições de vida e de relacionamento com o outro, em contextos diversos, inclusive na escola. (MONTOAN.p.8.2014.).

Sendo assim, devemos "cuidar" para que a escola venha a ser um espaço onde se respeite as diferenças e se aceite o outro como ele é, já que todos nós sofremos mutações ao longo de nossas vidas (WEIZENMANN, 2020). "O direito à diferença é determinante para que sejam cumpridas as exigências dessa educação, propiciando a participação dos alunos no processo escolar geral, conforme as capacitações de cada um". (MONTOAN. p.9.2014.). Á vista disso não somos nem seremos nunca iguais uns os outros sendo assim, é preciso reconhecer a escola como um espaço heterogêneo onde todos possam ter suas diferenças aceitas e respeitadas.
Segundo VALDEZ,

A escola é heterogeneidade, diversidade há de ser fonte de enriquecimento e de aprendizagem mútua. A família deve ser convocada e deve conhecer os projetos de inclusão de cada escola. Uma vez rompidos os preconceitos, as famílias costumam valorizar as práticas inclusivas nas escalas. (VALDEZ. P.20.2014.).

Sendo assim, fica explicito a importância da parceria família escola para chegar a uma educação inclusiva, significativa e de qualidade. A educação de todos e para todos é lei. Sendo assim, não pode ser vista como algo inalcançável é preciso engajamento na luta por direitos de igualdade onde todas as diferenças sejam respeitadas e sendo assim aceitas.

Diante disto, se faz essencial que ocorra a parceria com a família para que a mesma venha a acabar com as lendas que mesmo com muitas mudanças ainda existe de que a escola sozinha conseguir transformar a realidade de seus educandos e de que a mesma é responsável pela educação de nossos alunos quando na verdade sabemos que educação é dever da família a escola auxilia na busca e aquisição do conhecimento, e sabemos que isso só acontece quando se tem conhecimento da realidade do âmbito escola que encontrasse inserido na comunidade a qual se faz parte, portanto, é preciso que família e escola sejam parceiras na luta 
por uma educação inclusiva de qualidade para todos (WEIZENMANN, 2020).

\section{INCLUSÃO: A ACEITAÇÃO DA DIVERSIDADE HUMANA}

Partindo do pressuposto que somos todos diferentes com nossas dificuldades e anseios mesmo que não tenhamos deficiências físicas ou mentais devemos repensar e entender o que é de fato inclusão (PESQUISA, 2021).

Sabemos que nunca existiu nem tão pouco existirá uma sala de aula homogênea mesmo aquelas com alunos na mesma faixa etária e aparentemente sem nenhuma necessidade educacional especial, pois, cada pessoa aprende à sua maneira e a seu tempo. "Sabe-se que as pessoas aprendem em ritmos e estilos diferentes. Seus potenciais e suas limitações são bastante variados. Ainda assim, as aulas não são orientadas para essa diversidade, e tal fato começa a ser desnudado". (CARVALHO p.33.2014). É preciso que a escola utilize de diferentes mecanismos para $\mathrm{o}$ desenvolvimento intelectual dos educandos, pois quando se utiliza os mesmos recursos dificilmente se alcança a todos já que assim como pensamos diferentes temos também interesses distintos.

\section{Para CARVALHO,}

Não se pode esperar, evidentemente, que o professor desenvolva estratégias únicas para cada um dos estudantes; porém não é mais aceitável pensar a sala de aula do século XX pautada por um só texto, um só exercício, uma só proposta. O professor, nessa nova perspectiva, passa a ser um "designer de currículo", lançando mão de variados estratégias para mobilizar e desenvolver as competências de cada um dos alunos, sem, contudo, perder de vista os objetivos educacionais gerais que pautam sua ação docente". (CARVALHO.p.33.2014).

Sendo assim, está evidente que é preciso que o professor utilize diferentes métodos para que todos sejam alcançados respeitando assim os limites de cada estudante. É preciso incluir todos os conteúdos expostos em sala de aula independente de $\mathrm{o}$ estudante ter necessidade intelectual, física ou não. É preciso que se reconheça que a escola para ser inclusiva precisa estimular e tornar possível o acesso de todos ao conhecimento isso inclui os estudantes com deficiências física, intelectual, altas habilidades e também aqueles considerados "normais", ou seja, que não apresentam qualquer necessidade educacional especial.

\section{Segundo CARVALHO,}

As escolas precisam pensar a sala de aula como um espaço de aprendizagem pautada pela valorização da diferença, pelo conhecimento em redes, mas também devem reconhecer e informar à sociedade até que ponto elas poderão acolher e desenvolver, com responsabilidade e eficiência, crianças e jovens com necessidades especiais. Como qualquer instituição, a escola desenvolve maior ou menor expertise em determinados processos, sendo mais ou menos habilitada ao trato com determinadas síndromes, deficiências físicas ou outras manifestações. (CARVALHO, p.32.2014). 
Desta forma, podemos afirmar qual grandiosa se faz a escola no processo de inclusão, porém não podemos esquecer que a sociedade deve compreender sua importância perante esse fato já que nossas crianças e jovens com NEE fazem parte da mesma e devem sentir-se acolhidos (CIRÍACO, 2021). À vista disto, percebe-se que a troca de conhecimentos entre os educandos, ou seja, a convivência com o "diferente" muito tem contribuído na busca e aquisição dos conhecimentos, pois respeitando e valorizando $\mathrm{o}$ conhecimento do outro o nosso conhecimento só tende a crescer e multiplicar, sendo assim, destacamos aqui qual grandiosa e transformadora é a aceitação da diversidade humana.

\section{Diante disto, CARVALHO}

deixa claro que:

Muito precisa ser feito para que se conquiste a inclusão como expressão de qualidade na educação. Entender a diferença como valor é um passo a ser dado. Romper com a lógica da aula única, previsível, fechada e repetitiva é outro. Quando esses dois grandes passos tiverem sido dados, a chegada de um aluno com necessidades especiais não será mais vista como algo oneroso ou difícil, e sim como um processo natural, cujas práticas de intervenção docente, pautadas, pela diversidade didática, já estarão incorporadas - salvo casos muito específicos - ao cotidiano da sala de aula. Os resultados serão melhores para todos: destrutivamente, os diferentes alunos e cada um dos professores terão sido mobilizados a superar a si mesmo. (CARVALHO, p33.2014).

Entretanto, é preciso que a chegada dos alunos com NEE seja vista como algo que venha acrescentar os conhecimentos no espaço escolar já não se pode olhar para esses estudantes como diferentes ou anormais já que todos nós somos diferentes uns dos outros e temos nossas necessidades individuais a serem atendidas. Sendo assim, se faz de fundamental importância que o professor desenvolva aulas flexíveis que possam ser mudadas ou adaptadas às necessidades dos estudantes (PEREIRA, et al. 2019).

\section{CONCLUSÃO}

Ao termino deste estudo podemos concluir com a certeza de que a inclusão se faz de fundamental importância para o desenvolvimento de uma sociedade mais justa e solidaria. Porém sabemos que são inúmeros os desafios a serem enfrentados sendo que todos podem ser vencidos com dedicação e determinação.

$$
\text { E escola é por si um espaço }
$$

onde a heterogeneidade está em evidência, pois nela encontramos pessoas vindas de famílias distintas com diferentes histórias crenças, valores e ideologias. Desta forma, o papel da escola é fazer a integração de todos fazendo com que as diferenças venham a serem valorizadas, respeitadas e aproveitadas para a ampliação do conhecimento coletivo. 
Contudo, é preciso reconhecer que a escola deve buscar a parceria da família e da sociedade como o todo, pois quando o aluno é inserido no âmbito escolar já traz consigo sua vivencias e conhecimentos adquiridos anteriormente, ou seja, fora do espaço escolar, diante disto se faz indispensável que a comunidade e a escola estejam de fato integradas para que assim possa acontecer a inclusão de fato.

À vista disto, destacamos aqui a importância da aceitação da diversidade a qual encontramos na convivência escolar, o professor deve desenvolver suas atividades de forma flexível a qual venham alcançar a todos fazendo com que os educandos tenham acesso ao conhecimento ali exposto.

Já não é mais aceitável uma aula com um só método, pois sabemos que cada aluno aprende de uma forma, também não se pode preparar um método para cada educando isso é impossível, o que se deve fazer é utilizar formas de si alcance a todos procurando sondar e respeitar as dificuldades de cada um para que assim venha buscar estratégias que favorecem a aprendizagem e a ampliação do conhecimento.

Portanto, é preciso que vejamos a inclusão como uma pratica social e para que isso venha a ocorrer de fato é preciso que a escola e a comunidade trabalhem juntas, pois a aceitação da diversidade humana é o caminha para uma sociedade escolar mais justa e solidaria, sendo assim devemos "abraçar" a inclusão como tem quer ser de fato e direito já que as leis estão aí para garante uma educação inclusiva de qualidade a todos.

\section{REFERÊNCIAS}

BRASIL. Constituição da República Federativa do Brasil. Brasília: Imprensa Oficial, 1988.

BRASIL. Decreto no. 3.956, de 8 de outubro de 2001. Promulga a Convenção Interamericana Para a Eliminação de Todas as Formas de Discriminação Contra as Pessoas Portadoras de Deficiência. Guatemala: 2001.

CIRÍACO, F. L. Inclusão: um direito de todos Histórico do processo inclusivo. 2021. p. 1-6.

MANTOAN, M.T. Eglér. Diferenciar para incluir: a educação especial na perspectiva da educação inclusiva 22/09/2011.

http://diversa.org.br/artigos/artigos.php?id= 42\&/diferenciar_para_incluir_a_educacao_ especial_na_perspectiva_da_educacao_incl usiva acesso em 23/07/15.

PEREIRA, G. et al. Ouvindo imagens: ensaio sobre uma oficina audiovisual inclusiva de Listening images: essay on an inclusive cinema and education video workshop Introdução No âmbito da interface entre cinema e educação, uma série de práticas vêm sendo. 2019. p. 1-25.

PESQUISA, R. De. C apable of E nabling an I nclusive $\mathrm{P}$ erspective in $\mathrm{H}$ igher $\mathrm{E}$ ducation 1. 2021. p. 371-390.

REVISTA PATIO. Inclusão na escola das diferenças: É preciso desenvolver culturas inclusivas. VALDEZ, Daniel. ano 
VI. setembro/novembro 2014. grupo a. n²2. p.18-21.

REVISTA PATIO. Inclusão na escola das diferenças: qualidade e inclusão no ensino médio. MONTOAN, Maria Teresa Eglér. ano VI. Setembro/novembro 2014.grupo a. $n^{\circ} 22$. p.7-9.

REVISTA PATIO. Inclusão na escola das diferenças: uma mudança disruptiva. CARVALHO, Monica Tim de. ano VI. setembro/novembro 2014. grupo a. $\mathrm{n}^{\circ} 22$. p.30-33.

SILVA, N. C.; CARVALHO, B. G. E. Compreendendo o processo de inclusão escolar no Brasil na perspectiva dos professores: Uma revisão integrativa. Revista Brasileira de Educacao Especial, 2017. v. 23, n. 2, p. 293-308.

WEIZENMANN, L. S. et al. INCLUSÃO ESCOLAR E AUTISMO: SENTIMENTOS E PRÁTICAS DOCENTES School inclusion and autism: teachers' feelings and practices Inclusión escolar y autismo: sentimientos y prácticas docentes. [s.d.].2020. p. 1-8. 